\title{
Mutually Defined
}

National Cancer Institute

\section{Source}

National Cancer Institute. Mutually Defined. NCI Thesaurus. Code C69126.

Characterized or delimited reciprocally, in a mutual or shared manner. 